\title{
AUTONOMIA APARENTE: educação popular, sindicalismo e política na década de 1980, Criciúma (SC)
}

\author{
Rafael Pereira da Silva *
}

\section{Resumo}

Este artigo analisa a trajetória política do Centro de Estudos, Documentação e Informação Popular de Criciúma (CEDIP) desde sua fundação, em 1983, até o final desta década. Para tanto, observou-se a conjuntura política da cidade, além das articulações que o centro manteve com o Partido dos Trabalhadores (PT), a Central Única dos Trabalhadores (CUT), as associações de bairro e a Igreja Católica.

Palavras-chave: Sindicatos. Associações de Bairro. Partidos Políticos.

\section{Apresentação}

Em 1987, ocorria na cidade de Criciúma o processo que levou à falência a Companhia Brasileira Carbonífera Araranguá (CBCA). Há mais de um mês sem receber salários e correndo o risco de perder seus empregos, os mineiros decidiram montar um acampamento ao lado da estrada de ferro (NASCIMENTO, 2000) e paralisar o transporte do carvão, para dar mais visibilidade à sua luta. Uma vez montado o acampamento, começaram os conflitos.

A avenida principal do bairro Pinheirinho, por onde passava a ferrovia, virou um campo de batalha; mineiros de um lado, polícia militar de outro. A situação se tornava caótica na medida em que se improvisavam barricadas com latões e pedaços de madeira. Houve correria, explosões de bombas de gás lacrimogêneo, pedras atiradas de um lado para o outro.

\footnotetext{
* Doutorando em História na UNICAMP. Mestre em História Cultural pela UFSC. Bacharel e licenciado em História pela UFSC. E-mail: rapersilva@yahoo.com.br
} 
Durante os confrontos, os trilhos da estrada de ferro foram arrancados. Aos poucos, mais e mais pessoas se aglutinavam, entre mineiros de outras empresas, curiosos e moradores da região do confronto; estes “abriam suas portas” para abrigar trabalhadores em meio ao correcorre (FANTIN, 1992).

Esta descrição só foi possível mediante o registro visual feito pelo CEDIP (Centro de Estudos, Documentação e Informação Popular), que, dentre outras, tinha por função registrar a memória das lutas sociais na cidade de Criciúma. O registro audiovisual dos movimentos populares foi uma característica importante da década de 1980, período no qual se popularizou o acesso aos meios de produção de imagens. Além de registrar, os equipamentos de produção e exibição de vídeos passaram a ser cada vez mais utilizados nas atividades de educação e comunicação de entidades atuantes nos movimentos sociais, como sindicatos e organizações não-governamentais (ONGs). Segundo Henrique Pereira Oliveira, o acesso aos meios de produção audiovisual só foi possível graças à implantação de equipamentos em formato VHS (Video Home System) ${ }^{1}$ no mercado, que possibilitavam mais agilidade no registro dos movimentos sociais e na realização de vídeos populares (OLIVEIRA, 2001).

Hoje desativado, o CEDIP foi responsável por grande parte da história dos movimentos de trabalhadores na cidade. Em seu arquivo ${ }^{2}$, encontram-se fitas de vídeo, projetos que desenvolvia na área de formação sindical, educação popular, dossiês, resultados de pesquisas, recortes de jornais, documentos oficiais, estatutos, jornais sindicais, boletins informativos, entre outros. Desse modo, pensa-se que uma parte importante e muito rica da história dos trabalhadores da cidade pode ser posta em evidência.

\section{Contexto sociopolítico de Criciúma: formação do CEDIP}

Em 1976, a chapa do Movimento Democrático Brasileiro (MDB), formada por Murilo Canto e José Hülse, candidatos a prefeito e vice, respectivamente, perdera as eleições para a Aliança Renovadora Nacional (ARENA), que elegeu Altair Guidi. Isto ocorreu por dois motivos: força das elites locais subsidiadas pelo governo federal e forte discurso

\footnotetext{
${ }^{1}$ Em 1982, a Sharp lançou no mercado o primeiro videocassete nacional; em 1984, foi lançada a camcorder, em formato VHS.

${ }^{2} \mathrm{O}$ arquivo do CEDIP encontra-se no CEDOC (Centro de Documentação), ligado à Universidade do Extremo Sul Catarinense-UNESC.
} 
anticomunista $^{3}$. Para José Paulo Teixeira, falar em elites locais significava falar principalmente nos donos de minas, que, por anos, controlaram a política em Criciúma. Levando-se em conta o regime militar, nada mais "natural" que um discurso anticomunista, reforçado pelo fato de a cidade possuir forte histórico de luta operária. Entretanto, foi durante a gestão Guidi que o MDB - e o subsequente Partido do Movimento Democrático Brasileiro (PMDB) - se constituiu em forte partido popular (TEIXEIRA, 1999, p. 35).

O MDB vinha articulando-se a partir de um amplo trabalho de militância e formação de quadros, investindo na juventude e nas lideranças populares. Parte do trabalho se fazia nos finais de semana, nos quais se percorria casa por casa, bairro por bairro. Foi também nesse período que a economia do município se diversificou, com grupos ligados aos setores de vestuário, cerâmica, metalurgia, químico, serviços e transporte (Ibidem, p. 20).

Para se ter uma ideia da mobilização que acontecia na cidade, principalmente após o processo de abertura, o vereador Lírio Rosso, já do PMDB, discursara na tribuna da Câmara de Vereadores sobre uma passeata da Pastoral da Juventude, realizada em setembro de 1980:

...não poderia passar sem registro nesta casa, a realização da caminhada da libertação pela Pastoral da Juventude, em colaboração com os grupos de jovens das paróquias das Comarcas. As pesadas chuvas e o forte frio foram incapazes de impedir que cerca de 2 mil jovens percorressem, em caminhada, mais de $20 \mathrm{~km}$ por nossas ruas e nossos bairros (...). O sentido da caminhada foi religioso (...). Ao sentido religioso os jovens deram também um sentido social à caminhada. Foi feita uma correlação entre o povo hebreu, preso ao cativeiro, com suas misérias, suas fraquezas, suas descrenças, com os povos atuais, principalmente com o povo brasileiro: pobre, doente, sem instrução, sem terra em muitas vezes sem fé. ${ }^{4}$

No ano seguinte, em 29 de março de 1981, foi criada a Sociedade Amigos de Bairro (SAB) da Vila Manaus. A sociedade articulou-se com a participação de moradores ligados a outros movimentos, como a Pastoral Operária, militância do PMDB e do movimento operário

\footnotetext{
${ }^{3}$ Em 1973, ocorreu a chamada crise do petróleo; no Brasil, o governo Geisel propôs aos mineradores de Criciúma e região quintuplicar a produção de carvão mineral para abastecer o mercado interno. Foi o período no qual a indústria carbonífera mais se mecanizou, ganhando também muitos subsídios. O resultado final não foi o esperado, pois não se alcançou a meta proposta. Os mineiros não estavam preparados para o processo mecânico, o que gerou muitos acidentes de trabalho e aumentou os casos de pneumoconiose (doença irreversível). As máquinas não alcançarem o máximo de sua capacidade de produção, gerando prejuízo para os donos de minas, que não conseguiam cobrir os altos investimentos.

${ }^{4}$ ARQUIVO DA CÂMARA MUNICIPAL DE CRICIÚMA. Livro Ata da 68ª Sessão Ordinária, realizada em 22 de setembro de 1980. Em um livro-ata da Pastoral da Juventude de 1979, encontrado no CEDOC de Criciúma, percebe-se de que maneira a entidade se organizou na cidade. A ata 2, do segundo semestre de 1979, aponta: "Em 8 de agosto de 1979, às 20 horas, na Paróquia de São José, a convite do coordenador Dourival Giassi, a pastoral se reuniu para estruturar e organizar a Pastoral da Juventude da Comarca de Criciúma”.
} 
mineiro ligado ao Partido Comunista Brasileiro (PCB) (TEIXEIRA, 1999, p. 75). Esse período foi também o da retomada de um movimento sindical mais forte após anos de intervenção federal. Foi o período das lutas que vinham na esteira das greves do ABC paulista e do novo sindicalismo.

O novo sindicalismo foi amplamente trabalhado pela sociologia, assim como pela recente história social do trabalho. Ricardo Antunes definiu-o como um movimento originado em meados da década de 1970 que, "atuando por dentro da estrutura sindical, pouco a pouco, foi iniciando um lento processo de mudança e transformação desta mesma estrutura sindical atrelada” (ANTUNES, 1991). Armando Boito Jr. critica a ideia de "novo", ao referir-se à tutela do Estado. Afirma que, como não combate de fato a ordem capitalista vigente nem projeta uma mudança nas relações de produção, partindo para a negociação trabalhador/patrão sem intervenção estatal, a partir da organização pela base, “a tutela não é imposta à força pelo Estado sobre os sindicatos, mas é aspirada por sindicalistas que visam um modelo democrático de tutela” (BOITO JR., 1991).

Contudo, no campo historiográfico, Marcelo Badaró Mattos afirma que o conceito foi criado em meados da década de 1970 por estudiosos e militantes do movimento sindical operário. Tal termo se opunha a um suposto "velho sindicalismo", tanto o do regime militar, silenciado pelos "anos de chumbo", quanto o do período anterior ao golpe, denominado "sindicalismo populista” (MATTOS, 1998, p. 11).

Em relação às oposições sindicais, Badaró Mattos observa que só conseguiram espaço após o efeito dominó das greves do ABC paulista. Justamente por isso, anos depois, os que defendiam uma nova ação paralela à estrutura sindical tenderam a constituir a minoria, enquanto a maior parte das oposições buscava alcançar a direção dos sindicatos pela via eleitoral (Ibidem, p. 79).

Através da análise dos artigos da coletânea $\mathrm{Na}$ luta por direitos: estudos recentes em história social do trabalho (FORTES, 1999), é possível ter-se uma visão abrangente desse debate. A sociologia anterior à década de 1970 ajudou a criar a imagem de uma classe trabalhadora passiva, por conta de sua origem rural, portanto, desprovida de uma “consciência de classe”, razão por que deveria ser negada pelos "novos” e incluída num sistema populista cujo órgão de representação, o sindicato, fosse atrelado ao Estado.

Por outro lado, quando lutavam por algum direito, esses trabalhadores eram orientados por uma cúpula sindical, portanto, alheios à organização política de base. A denominação novos deve ser observada em seus limites e num contexto específico: o do debate 
historiográfico da década de 1980. A sociologia e a história utilizaram, durante certo tempo, a roupagem do populismo para explicar os movimentos de trabalhadores no período 1945-1964, desconsiderando seus pormenores ou entendendo-os como passíveis de cooptação por sindicatos atrelados; não podemos cometer o mesmo equívoco. Neste sentido, a ideia de novos contém elementos de negação de um passado que se quer apagado (Ibidem, 1999).

A retomada de um novo sindicalismo via processo eleitoral foi observada em Criciúma na década de 1980, em meio às comemorações do centenário do município. Como de praxe, foi uma festa criada pela elite da cidade, em parceria com o poder municipal. As pessoas passaram a reinterpretar a cidade, num período em que se inauguravam obras e monumentos. A Festa do Centenário "legitimou” a ideia de uma cidade que cresceu e se consolidou graças ao esforço de seus antepassados, pertencentes às cinco etnias fundadoras do município: italianos, alemães, poloneses, portugueses e afrodescendentes.

Desejava-se igualmente mascarar o estigma de uma cidade industrial mineira; assim, os mineradores não participaram efetivamente das comemorações, pois ficaram envolvidos com a Expo 100, feira industrial e comercial ocorrida em outubro de 1980. Para completar os discursos, "inventados" nos gabinetes a "toque de caixa”, projetaram-se obras e monumentos para “imortalizar” os primeiros imigrantes (CAMPOS, 2003).

Verifica-se, por trás de uma festa comemorativa, a existência de um campo de disputa política, bastidores nos quais se discutia o formato da festa e a quem ela poderia interessar naquele momento. As autoridades procuravam, num reconhecimento através das comemorações do Centenário, um aval da população. O que se procura perceber é justamente a disputa por espaço, os conflitos e as tensões:

Através delas se poderá espiar uma rica miríade de práticas, linguagens e costumes, desvendar disputas em torno de seus limites e legitimidade, ou na atribuição de significados, e sentir as tensões latentes sobre as formas lúdicas. Apurando o ouvido, se poderá captar manifestações de dor, revolta, alegria, presentes nos dias de festa como nos dias comuns, e testemunhar reconciliações ou desentendimentos que, para o historiador, têm sempre um gosto único e inconfundível (CUNHA, 2002, p.12).

À medida que ocorriam os festejos, o PMDB cada vez mais se organizava internamente. Em outubro de 1981, ocorreu o I Seminário Nacional de Prefeitos do partido, no qual foram debatidas as experiências populares de administração municipal, com o intuito de se preparar as eleições do ano seguinte (TEIXEIRA, 1999, p. 45). Os nomes começaram a ser decididos e optou-se por uma aliança com o Partido Progressista (PP), a fim de conseguir 
votos de setores mais conservadores da cidade. Foram indicados o engenheiro José Augusto Hülse (PMDB) para prefeito e Roseval Alves, do PP, para vice. Neste sentido, a chapa conseguiu aglutinar representantes do empresariado local, como Realdo Guglielmi, além de ex-membros da ARENA, que não se viram representados pelo candidato do Partido Democrático Social (PDS). Este foi o quadro que resultou na vitória do PMDB nas eleições de 1982 (Ibidem, p. 47).

Entre 1983 e 1988, ampliou-se o diálogo entre os movimentos sociais organizados e a prefeitura. A questão de vencer as eleições com apoio de setores mais conservadores fez surgir certo mal-estar no secretariado que se formou, pois cargos tinham que ser distribuídos. Mesmo assim, alguns avanços foram conquistados. Para citar um exemplo, os seminários de organização e mobilização comunitária.

O primeiro ocorreu em 3 de julho de 1983, logo no início da administração. Os seminários foram desenvolvidos pelo Departamento da Promoção Social da Secretaria de Saúde e Bem-Estar. Participavam associações de moradores, sociedades amigos do bairro (Sabs), associação de pais e professores (APPs), grupos de jovens, clubes de mães, centros comunitários, entre outros. O objetivo era debater demandas sociais, avaliar o governo, além de discutir a conjuntura nacional. A rigor, esses eventos serviam mais para troca de esclarecimentos e debates do que para definir estratégias ou políticas governamentais (Ibidem, p. 89-90). Existia certo espaço democrático de participação, no qual se podia perceber uma série de organizações populares, que, se não decidiam as políticas públicas, ao menos se faziam ouvir, fato que não ocorria nos anos anteriores.

Foi durante a administração Hülse que começou o desmonte da economia carbonífera, aspecto que não dizia respeito diretamente à prefeitura, pois quem subsidiava o carvão era o governo federal. Inicialmente, o impacto desse desmonte só não foi mais acentuado por conta do processo de diversificação econômica. As indústrias de cerâmica, calçados, vestuário, plásticos e descartáveis davam outra dinâmica à “cidade do carvão”, que, após o centenário, passou a ser a "cidade do imigrante”.

Segundo Goularti Filho, a crise do carvão se agravou de maneira mais explícita a partir de 1986. Isso pode ser observado pelos dados referentes à produção e oferta de empregos no setor. Em 1989, foram extraídos 13,9 milhões de toneladas carvão de ROM ${ }^{5}$, volume que em 1991 caiu para 6,7 milhões; a oferta de emprego, consequentemente,

\footnotetext{
${ }^{5}$ O carvão ROM (Run Of Mine) é o que sai do subsolo em estado bruto. Serve para diversas indústrias de processamento, como química, metalúrgica e termoelétricas.
} 
despencou de 7,9 mil para 4,4 mil. Para completar a crise, o governo ficou 16 meses sem pagar as cotas já adquiridas (GOULARTI FILHO, 2002, p. 344). Por outro lado, embora a crise do complexo carbonífero se tenha iniciado na década de 1980, entre 1982 e 1985 a região teve uma grande produção, fazendo com que a taxa de empregos se mantivesse. Nesses quatro anos, a produção total de carvão ROM superou toda a produção da década de 1970: foram produzidos 6,9 milhões de toneladas, contra 6,7 milhões de 1970 a 1979. A produção anual do carvão superou os 15 milhões de toneladas e a oferta de emprego se manteve acima de 10 mil empregos diretos (MORAES, 2003, p. 101).

Outro fator que contribuiu para a crise foi o aumento populacional em um período de queda na oferta de empregos. Ou seja, entre 1980 e 2000, a população de Criciúma passou de 110.604 para 170.274 habitantes (GOULARTI FILHO, 2002, p. 440). A produção decresceu em média 18\% ao ano entre 1985 e 1990, caindo de mais de 19 milhões de toneladas para 7,4 milhões produzidos em 1990, reduzindo a oferta de emprego para 4.530 trabalhadores, menor do que a de 1950, quando havia 5.500 trabalhadores (MORAES, 2003, p. 102).

Durante o governo Collor, foi dado o golpe definitivo. As práticas neoliberais colocaram à venda várias empresas até então estatais, entre elas a Companhia Siderúrgica Nacional (CSN). Segundo Goularti Filho:

O governo Collor simplesmente liberou a importação do carvão metalúrgico, desobrigou as siderúrgicas estatais de comprar o carvão nacional, acabou totalmente com as cotas e fechou o Lavador de Capivari. As unidades da ICC [Indústria Carboquímica Criciúma] em Imbituba e Criciúma foram fechadas em 1994. Associado a essas medidas iniciou o processo de privatização, que atingiu diretamente a Cia. Próspera, subsidiária da CSN, demitindo mais de 1500 trabalhadores. Os trabalhadores da Próspera ficaram um ano e oito meses num movimento de resistência à privatização da empresa, aguardando uma reversão da política econômica em prol da estatal. A solução veio com a venda da estatal para a Metropolitana, criando a Nova Próspera. Como a nova empresa não cumpriu os prazos estabelecidos e ficou impossibilitada de minerar numa área de preservação ambiental, a Próspera novamente voltou às mãos da CSN, agora privatizada, que fechou definitivamente em 1995 (GOULARTI FILHO, 2002, p. 343).

Os conflitos relatados no início deste artigo referem-se ao processo de falência da antiga Companhia Brasileira Carbonífera Araranguá (CBCA), que se concretizou em 1987, deixando muitos trabalhadores sem emprego. Todavia, uma mobilização iniciada no sindicato alterou a história. Os mineiros organizados tomaram para si a "massa falida", que mais tarde se tornou a Cooperativa de Extração de Carvão Mineral dos Trabalhadores de Criciúma 
(COOPERMINAS), existente até hoje. A experiência de tomar para si os meios de produção foi algo inédito na história dos trabalhadores de Criciúma, que, durante os anos 80, após as vitórias das oposições sindicais, responsabilizaram-se por tornar a região um verdadeiro “caldeirão” de greves, reivindicações e conflitos contra os mineradores, o governo e as elites locais.

A história dessa experiência foi contada por Márcia Fantin, na época em que ainda participava do CEDIP. Segundo a própria autora, na introdução do seu trabalho:

o interesse em estudar a experiência dos mineiros da CBCA foi impulsionado, de um lado, pelo vínculo e trabalho de assessoria junto aos mineiros, desenvolvido pela equipe do CEDIP da qual faço parte desde 1985 (FANTIN, 1992, p. 11).

\section{O Centro de Estudos, documentação e informação popular (CEDIP)}

Em reunião realizada dia 3 de setembro de 1983, na Rua Henrique Lage, no município de Criciúma, às 18h30, fundava-se o CEDIP, Centro de Estudos, Documentação e Informação Popular de Criciúma. A ata de fundação continha seu primeiro estatuto (todo ele manuscrito). Tinha como finalidade:

\footnotetext{
${ }^{6}$ CEDOC. Arquivo do CEDIP. Ata de fundação de 1983. No documento não consta outra referência além do ano citado. Pasta 7(204).
}

Coletar e documentar toda e qualquer publicação elaborada por entidades populares, tais como folhetins, panfletos, jornais, livretos, manifestos etc; promover e apoiar todas as formas de organização, documentação e informação da cultura popular; desenvolver e publicar pesquisas e estudos voltados aos interesses dos movimentos populares; recuperar a memória histórica dos movimentos populares através de estudos e pesquisas; realizar cursos, seminários, palestras e debates sobre a realidade social econômica e política, cultural e religiosa; avaliar e sistematizar resultados de experiências de educação, organização e articulação do movimento popular; incentivar a participação, organização e solidariedade, estimulando para, esse fim, atividades, movimentos, entidades e associações populares e por fim estar a serviço do movimento popular. ${ }^{6}$ 
Assinaram a ata de fundação do centro: Ivo Riguetto Filho, Marli de Oliveira Costa, Fábio Zarbato, Regina T. Felisberto, Nilzo Felisberto, Maria B. Teixeira, Dorval do Nascimento, João Paulo Teixeira, Maria Rosângela Marcelino, Marco Antônio Fraga, Norberto Zanboni, José Paulo Teixeira, Antônio Luiz Miranda, Márcia Fantin, Maria Isabel de Moura Brito, Ilma Salete de Morais, Nivaldo A. Goularti e Odelondes de Souza.

Quem eram essas pessoas que passaram grande parte da década de 1980 militando nos movimentos sociais da cidade? Por que resolveram montar um centro de assessoria popularsindical? Que ligações esse centro mantinha com outras instituições? Que atividades realizavam? Essas são algumas indagações que nortearão o restante o texto.

Como já foi dito, Criciúma era um palco de conflitos no qual atuava uma série de movimentos sociais. Partindo desse princípio, é possível mapear alguns nomes que já militavam antes de integrarem o CEDIP. Entre estes, encontram-se Dorval do Nascimento, Regina Teixeira, Maria Bárbara Teixeira, João Paulo Teixeira e José Paulo Teixeira.

A maioria deles era estudante secundarista no final da década de 1970 e início dos anos 80; militava em grupos de jovens da Igreja Católica ligados à Pastoral da Juventude, onde se reuniam nos fins de semana. Nessa época, formaram o grupo Nosso Ideal é Jesus Cristo (NIJC). A maioria estudava no Colegião (escola pública da cidade) e lá também exercia atividades de militância política. Este mesmo grupo do NIJC se articulou, formando uma chapa para a eleição do centro cívico da escola, denominada Outras Palavras. Saiu vencedor do pleito e mais tarde fundou a União Criciumense de Estudantes Secundaristas (Uces). Também nessa época, mais precisamente em 1982, passou a militar no PT. Pessoas ligadas a movimentos de bairro, como João Paulo Teixeira, presidente da SAB Vila Manaus, fundada em 1981, também fizeram parte desse contexto. Ainda nessa época, tiveram contato com José Paulo Teixeira, estudante de Ciências Sociais da Universidade Federal de Santa Catarina (UFSC) e um dos fundadores do PT em Criciúma, em 1982.

Destaca-se, nesse contexto, a atuação dos irmãos Teixeira: Bárbara, Regina, João Paulo e José Paulo. Integravam um grupo que realizava leituras sobre marxismo, conjuntura nacional, ditadura militar, América Latina, entre outras temáticas. Surgiu daí a idéia de fundar um centro de assessoria aos movimentos sociais, do qual o grande "animador" e articulador seria José Paulo Teixeira ${ }^{7}$.

O CEDIP surgiu num período de abertura política e vitória da oposição na cidade PMDB -, do surgimento do PT no município em 1982 e em meio a uma “nova” maneira de se

\footnotetext{
${ }^{7}$ Dados obtidos em entrevista realizada em 27 de outubro de 2004 com Dorval do Nascimento, na cidade de Criciúma, onde reside.
} 
fazer militância, por meio de educação popular, de base, pelas oposições sindicais. Esta característica foi ressaltada por Maria da Glória Gohn, ao afirmar que a educação popular foi uma demanda presente em vários movimentos sociais organizados. Grupos de assessoria advindos das universidades ou ONGs de trabalho comunitário também representaram fontes importantes da educação popular produzida (GOHN, 1994, p. 64).

O trabalho de educação popular realizado pelo CEDIP é observado na análise de Paulo Meksenas sobre os movimentos sociais dos anos 1980, que, passando por um processo de institucionalização, foram os condutores de algumas lutas sociais, atuando em diversos setores. Neste sentido, salienta o autor:

O processo e a dinâmica das lutas no seio do capitalismo contribuíram, em muitos casos, para a institucionalização dos movimentos sociais que se converteram em organizações não-governamentais. Noutros contextos, ocorreu o contrário, questões e temas das lutas sociais foram propostos pelas ONGs e, posteriormente, encampados pelos movimentos sociais (MEKSENAS, 2002, p. 153).

Isto significa dizer que, no processo de abertura política ocorrido no início dos anos 80, e com a reestruturação sindical em Criciúma, o CEDIP teve papel fundamental na formação popular e na consequente vitória de várias oposições sindicais na cidade.

O CEDIP definia-se como entidade civil sem fins lucrativos, político-partidários ou religiosos $^{8}$, características contidas na sua ata de fundação. Na prática, observa-se o contrário. Cruzando as informações desta ata com as de reuniões do Diretório Municipal do PT a partir de $1983^{9}$, constata-se que os nomes são os mesmos, ou seja, tudo leva a crer que o centro poderia ser visto como um projeto político do Partido dos Trabalhadores de Criciúma; pelo menos, de parte deste.

Observa-se um exemplo dessa ligação do centro com o Partido dos Trabalhadores a partir da eleição de José Paulo Teixeira como vereador nas eleições municipais de 1988, com 706 votos. Em uma reunião do Diretório Municipal do partido, em 10 de janeiro de 1989, José Paulo Teixeira afirmou que o PT assumira a relatoria da Constituinte Estadual, criando a Plenária Pró-Participação Popular. Informou também, na reunião, que pretendia se reunir com

\footnotetext{
${ }^{8}$ CEDOC. Arquivo do CEDIP. Ata de fundação do CEDIP 1983. Pasta 7 (204), p. 1.

${ }^{9}$ Dados das atas das reuniões do Diretório Municipal do PT, período entre 1983 e 1987.
} 
lideranças de entidades populares da cidade, a fim de tentar organizar uma plenária popular municipal $^{10}$.

O mesmo debate, feito internamente no PT, era tornado público por um artigo publicado no Boletim Movimento Vivo, informativo do CEDIP. Neste, Teixeira afirmava que o debate constituinte estava em curso e convocava as lideranças populares, sindicais, estudantis, pastorais e ecológicas a participar. Nesse texto, há um “chamado” à participação popular, em contraposição ao poder de algumas famílias que controlavam os rumos da cidade. "Vamos fazer uma lei orgânica democrática e popular. A luta já começou. O que vai prevalecer? O poder popular ou o poder de algumas famílias e grupos econômicos que mandam e desmandam em nosso município?”11

Além do PT, pode-se observar a ligação do CEDIP com grupos da ala progressista da Igreja Católica, movimentos de bairro, sindicatos locais e a CUT. Em relação à Igreja, constata-se, através dos documentos internos do centro, forte ligação no que se refere às práticas de atuação, a partir de uma democracia de base, de um projeto popular de organização comunitária. Em uma carta enviada ao CEDIP no dia 23 de dezembro de 1987, os padres Ângelo Bussolo, coordenador diocesano de Pastoral e Domingos Nandi, responsável pelo setor de Comunicação da Diocese, apontam o CEDIP como um órgão indispensável para a cidade de Criciúma. Além disso, completam: “o CEDIP está sendo um órgão, uma entidade de grande utilidade para a conservação das lutas populares, através do seu serviço de documentação"12.

Quanto aos movimentos de bairro, o centro organizou, no dia 30 de agosto de 1986, o Seminário sobre Movimentos de Bairro. Neste, procurou avaliar a atuação dos movimentos existentes e tentou articular a organização de uma federação ou união de organizações de bairro. O seminário contou com representantes de sete organizações, entre as quais Vila Manaus, São Francisco, Operária Nova, Vila Francesa, Ceará, São Sebastião e Vila Zuleima. Publicou-se, ainda pelo CEDIP, um relatório que informava os resultados do seminário. Notase no documento a ênfase na auto-organização comunitária como resultado da ampla articulação de base que se daria a partir da consolidação de uma federação ou união de bairros. A ideia da federação já tinha sido aventada pelo do poder público municipal; entretanto, uma vez organizada pela base, combatia justamente a possível intervenção do

\footnotetext{
${ }^{10}$ DIRETÓRIO MUNICIPAL DO PARTIDO DOS TRABALHADORES DE CRICIÚMA. Ata da reunião do dia 10 de janeiro de 1989.

${ }^{11}$ BOLETIM MOVIMENTO VIVO. n 5. Ano 1. Criciúma: CEDIP. Agosto/setembro de 1989.

${ }^{12}$ Carta enviada ao CEDIP pela diocese de Tubarão em 23/12/87. CEDOC, arquivo do CEDIP.
} 
governo na articulação dos movimentos sociais. Nesse processo de construção, caberia ao CEDIP o papel de assessoria, contribuindo para que a iniciativa tivesse sucesso ${ }^{13}$.

À medida que analisamos a documentação do centro, verificam-se relações cada vez mais próximas entre o conjunto de alguns movimentos sociais de Criciúma e o CEDIP. Percebe-se a circulação das pessoas entre as diversas entidades de oposição, ligadas também a um contexto mais amplo, característico dos anos 80: as oposições sindicais, o novo sindicalismo e a CUT.

Na cidade, diversas oposições venceram as eleições sindicais. Parte desse processo explica-se pela formação da CUT em nível nacional, em agosto de 1983, no I Congresso da Classe Trabalhadora (CONCLAT). Uma de suas preocupações iniciais dizia respeito à formação sindical, precisamente com a criação da Secretaria Nacional de Formação, em 1984, no I CONCUT (Congresso da CUT). Segundo a versão da entidade, a data de início das atividades de formação sindical é 1987, fato que corresponde também ao início das atividades de duas das principais escolas que realizavam a formação da militância cutista: o Instituto Cajamar, de São Paulo, de 1986, e a Escola Sindical 7 de Outubro, de Belo Horizonte, em 1987 (TUMOLO, 2002, p. 110).

A versão oficial da CUT para o início das atividades de formação foi questionada por Paulo Sérgio Tumolo, ao constatar que as políticas de formação começaram em 1984 e, nesse período, ou mesmo antes, já havia grande quantidade de entidades organizadas do movimento social que, entre outras tarefas, faziam a formação de muitos militantes, inclusive da CUT (Ibidem, p. 141).

Ainda segundo Tumolo, os programas de formação tiveram dois nascedouros. O primeiro, da própria prática, ou seja, das demandas do próprio movimento sindical cutista, particularmente das oposições sindicais. A Secretaria de Formação deveria oferecer a essas oposições o suporte necessário não apenas à luta de “derrubada dos pelegos” e conquista dos sindicatos, mas, acima de tudo, apoderar-se deles em seguida. Por outro lado, a formação não poderia ficar à mercê das demandas, e exigiam-se cursos de formação básica que abarcassem questões como o modo de produção capitalista, a história do movimento operário e sindical, a luta de classes, o socialismo (Ibidem, p. 149-50).

Este contexto, relacionado tanto à construção do "novo sindicalismo", quanto aos cursos de formação baseados nas “cartilhas” da CUT, é observável no CEDIP e na sua relação

\footnotetext{
${ }^{13}$ Resultados do Seminário sobre Movimentos de Bairro. CEDOC, arquivo do CEDIP.
} 
com os sindicatos locais. As vitórias das oposições sindicais dos vestuaristas e calçadistas, em 1984, dos mineiros de Criciúma, em 1986, e do Rio Maina, em 1988, impulsionaram as atividades de assessoria e formação realizadas pela equipe do centro.

No informativo de abril de 1987, percebe-se que a vitória da chapa de oposição do Sindicato dos Mineiros de Criciúma fez com que o centro assinasse um convênio com o órgão, fazendo funcionar, a partir de maio de 1987, a Escola Sindical Mineira. Segundo o documento:

Criada pela assessoria de Formação Política e Sindical, constituída pela equipe do CEDIP e liderança dos mineiros, tem como objetivo a formação de lideranças dos mineiros de Criciúma, e funcionará na sede do Sindicato. A Escola é resultado de um projeto da equipe do CEDIP e da diretoria do Sindicato. Para este primeiro semestre está previsto um Curso básico de Sindicalismo, que será oferecido para cerca de 20 a 40 mineiros de acordo com os turnos na mina. As aulas serão semanais e o curso terá 3 meses de duração. O curso atingirá uma média de 90 lideranças no trimestre (abril, maio, junho) e será ministrado por professores do CEDIP e Assessores convidados $^{14}$.

No informativo, também constam outros cursos de formação básica, como o Intensivo de Formação dos Vestuaristas, que “atingirá cerca de 120 operários de base e formará aproximadamente 30 lideranças vestuaristas e calçadistas por trimestre (abril, maio e junho), num total de 240 operários e 60 lideranças (agosto, setembro, outubro)”. Estão listados ainda os cursos de Imprensa Sindical (12h/aula), Legislação e Convenção Coletiva (12h/aula), Curso Básico de Sindicalismo (14h/aula), Comunicação e Expressão (40h/aula), Administração Sindical (40h/aula), Sindicalismo Rural (40h/aula), Formação de Lideranças Comunitárias (40h/aula), Os Primeiros Passos do Marxismo (45h/aula) ${ }^{15}$, para apenas citar alguns.

A partir dessas articulações do CEDIP com os sindicatos, o PT, a CUT, os movimentos de bairro e as pastorais, fica evidente que havia naquele momento uma composição de forças políticas - de um lado, os "donos da cidade"16; do outro, as “articulações de esquerda” -, que tinham como foco central de atuação o Sindicato dos Mineiros de Criciúma. Este, nos momentos de greve geral, conseguia mobilizar toda a cidade.

\footnotetext{
${ }^{14}$ INFORMATIVO CEDIP de abril de 1987. Ano 3, n. 10. CEDOC, Arquivo do CEDIP.

${ }^{15}$ Idem.

${ }^{16}$ A expressão "donos da cidade” é de José Paulo Teixeira, um dos idealizadores do CEDIP e um dos fundadores do PT em Criciúma. A expressão se referia aos grupos familiares que detinham o poder econômico e político da cidade, famílias que cresceram juntamente com a economia carbonífera a partir dos anos 1920 e assim mantiveram-se até meados dos anos 90, quando a economia carbonífera começou a desabar.
} 
Mas a esquerda em Criciúma, nos anos 80, não se constituía como um "bloco” homogêneo; havia disputas internas nos vários segmentos que a compunham, na qual nomes de pessoas circulavam por diversas “siglas”. Por essa perspectiva, o nome de José Paulo Teixeira é emblemático.

Em relatório de 1985 da reunião de articulação de candidaturas comprometidas com os movimentos populares e com a luta dos trabalhadores da região sul de Santa Catarina, à qual compareceram 50 pessoas ligadas a diferentes movimentos sociais (bairros, sindicais, estudantis, ecológicas e pastorais) e ao PT, é possível averiguar os objetivos dos segmentos da esquerda. Naquele momento, discutia-se a articulação dos movimentos populares em torno do PT:

A reunião teve um grande significado político, pelo fato de o PT ter reunido pessoas representativas dos vários movimentos populares, e que hoje, após os excelentes resultados obtidos nas eleições em várias capitais do país o PT se fortalece e se insurge como uma alternativa real, viável e diferente para os trabalhadores, a juventude e as demais forças populares (INFORMATIVO CEDIP, 1985).

A partir dessa articulação, observam-se nomes que também faziam parte do CEDIP. A coordenação, por exemplo, era constituída, entre outros, por José Paulo Teixeira, secretário de Formação Sindical da CUT Regional Sul, membro do CEDIP e presidente do PT em Criciúma; Valdeci José da Silva, presidente do Sindicato dos Vestuaristas e secretário geral da CUT Sul; Amilton Borges, presidente da CUT/Sul; João Paulo Teixeira, coordenador da Pastoral Operária; Dorval do Nascimento, membro do CEDIP e da Executiva do PT de Criciúma.

Nota-se, a partir da listagem, que havia articulação entre pessoas ligadas a vários setores como o PT, a CUT, os sindicatos, a Igreja, o CEDIP, o que nos leva a pensar que havia de fato um projeto das esquerdas. Este, passando pelo crescimento do Partido dos Trabalhadores, pela formação sindical e pelas vitórias das oposições nos sindicatos, dentre os quais o CEDIP, como instituição de assessoria, exercia um papel fundamental. Tanto que José Paulo Teixeira aparece citado no relatório como um grande articulador, exercendo, ao mesmo tempo, a presidência municipal do PT, a secretaria de Formação Sindical da CUT/Sul e atividades no CEDIP. 


\section{Considerações finais}

Do final dos anos 1980 em diante, a manutenção do CEDIP tornou-se inviável pela própria dinâmica que a cidade impôs. Neste sentido, devem ser ressaltados alguns fatores e consequências desse desmonte. Um dos motivos foi a ampliação do espaço de atuação do PT frente ao PMDB, até então o principal partido de oposição da cidade. Ao mesmo tempo, o CEDIP se estruturava e já realizava uma série de atividades em conjunto com os mineiros, forte reduto eleitoral do Partido dos Trabalhadores. Na medida em que o partido crescia e o CEDIP centralizava as demandas de formação política da região, os conflitos também se tornavam visíveis.

Desse modo, ficou evidente uma disputa no próprio PT, a partir de duas correntes internas: de um lado, os “intelectuais” que atuavam no CEDIP, cujo principal nome era José Paulo Teixeira; de outro, o grupo dos “mineiros”, liderado pelo então presidente do sindicato, José Paulo Serafim. As disputas internas do PT de Criciúma tiveram como marco as eleições municipais de 1988. De acordo com as fontes pesquisadas, isto resultou na mudança de posição do CEDIP na década seguinte. Como desdobramento desses conflitos, passaram a ser boicotadas várias iniciativas do CEDIP, como a Escola Sindical Mineira, cursos de formação e assessoria.

Desse modo, o CEDIP tomou iniciativas no sentido de profissionalizar suas atividades e dialogar com outros setores da sociedade civil. Contando com um grupo de voluntários e novos integrantes, deslocou seus projetos da área sindical para o setor de comunicação popular e os debates políticos. Ao assumir essa faceta, também teve que criar uma nova identidade, deixando de lado sua atuação popular-sindical, tornando-se uma organização-não governamental (ONG).

Na nova fase, o conceito de cidadania passou a fazer parte do discurso do CEDIP, que se tornava mais "acadêmico". Um dos projetos no qual se observou, de forma clara, essa mudança foi a criação do Núcleo de Estudos da Cidade, espaço de discussões interdisciplinares no qual seus integrantes passaram a discutir a cidade por um viés mais teórico.

Os resultados desses debates puderam ser vistos na revista Retratos da Cidade e nos artigos semanalmente publicados no Jornal da Manhã, entre os anos de 1995 e 1996. 
O que busquei neste artigo foi observar as mudanças ocorridas na cidade, através da trajetória de atuação de membros do CEDIP, percebendo-o como um local de constantes disputas políticas que se refletiam em outros setores de atuação desses mesmos personagens.

\section{AUTONOMY APPARENT: popular education, trade unionism and politics in the 8o's in Criciúma (SC)}

\section{Abstract}

This article analyzes the political trajectory of the Center of Studies, Documentation and Popular Information of Criciúma (CEDIP) since its establishment, in 1983, until the late 1980s. For that, the political situation of the city, besides the articulations the Centre mantained with the Partido dos Trabalhadores, CUT, Neighborhood Associations and the Catholic Church, was observed.

Keywords: Syndicates. Neighborhood Associations. Parties.

\section{Referências}

ANTUNES, Ricardo. O novo sindicalismo. São Paulo: Brasil Urgente, 1991.

BOITO JR., Amando (org). Reforma e persistência da estrutura sindical brasileira. O sindicalismo brasileiro nos anos 80. Rio de Janeiro: Paz e terra, 1991.

CAMPOS, Emerson Cesar. Territórios deslizantes: recortes, miscelâneas e exibições na cidade contemporânea-Criciúma (SC) (1980-2002). 2003. 214 f. Tese (Doutorado em História). Centro de Filosofia e Ciências Humanas, UFSC. Florianópolis.

CUNHA, Maria Clementina Pereira. Carnavais e outras f(r)estas: ensaios de história social da cultura. Campinas (SP): Ed. UNICAMP, 2002.

FANTIN, Márcia. Os significados da experiência de gestão de uma mina pelos trabalhadores em Criciúma/SC: nas malhas das relações de poder. Florianópolis, 1992. 200 f. Dissertação (Mestrado) - Centro de Filosofia e Ciências Humanas, UFSC. 2003.

FORTES, Alexandre (org.). Na luta por direitos: estudos recentes em história social do trabalho. Campinas: Unicamp, 1999.

GOULARTI FILHO, Alcides. Formação econômica de Santa Catarina. Florianópolis: Cidade Futura, 2002. 
GOHN, Maria da Glória. Movimentos sociais e educação. 2. ed. São Paulo: Cortez, 1994.

MATTOS, Marcelo Badaró. Novos e velhos sindicalismos. Rio de Janeiro (1955/2988). Rio de Janeiro: Vício de Leitura, 1998.

MEKSENAS, Paulo. Cidadania, poder e comunicação. São Paulo: Cortez, 2002.

MORAES, Fábio Farias. O carvão catarinense e o planejamento estatal. In: FILHO, Alcides Goulart. Ensaios sobre a economia sul-catarinense. Criciúma: UNESC, 2003.

OLIVEIRA, Henrique Luiz Pereira. Tecnologias audiovisuais e transformação social o movimento de vídeo popular no Brasil (1984-1955). 2001. 487 f. Tese (Doutorado) Pontifícia Universidade Católica de São Paulo. São Paulo.

TEIXEIRA, José Paulo. Nos tempos do Zé: um estudo sobre o PMDB e o governo popular em Criciúma (1983-1988). Florianópolis: Cidade Futura, 1999.

TUMOLO, Paulo Sérgio. Da contestação à conformação: a formação sindical da CUT e a reestruturação capitalista. Campinas: Editora da Unicamp, 2002.

Recebido em: Julho/2010 Aprovado em: Outubro/2010 